\title{
SWIFT SYNTHESIS OF ZnO NANORODS BY MICROWAVE HYDROTHERMAL METHOD
}

\author{
MADUNURI CHANDRA SEKHAR $^{\mathbf{1}} \boldsymbol{\&}$ M. VENKATA RAMANA ${ }^{\mathbf{2}}$ \\ ${ }^{I}$ Department of Physics, Rayalaseema University, Kurnool, Andhra Pradesh, India \\ ${ }^{2}$ Department of Physics, Govt. Arts \& Science College, Kothagudem, Telengana, India
}

\begin{abstract}
A new, simple, large yield, low cost, microwave assisted hydrothermal method to synthesize high quality ZnO nanorods has been adopted. The microwave assisted hydrothermal synthesis method brought significant benefits like greater speed and yield compared to the traditional methods. The present article utilized zinc acetate, sodium hydroxide solutions as precursors which exerted a tremendous effect on morphology and size of ZnO nanorods. The scanning electron microscoping (SEM), X-ray diffraction (XRD), UV Spectroscopy, FTIR analysis revealed the morphology and particle size of $\mathrm{ZnO}$ nanorods having around 40nanometer in diameter and $0.8 m i c r o m e t e r$ in length formulate $150^{\circ} \mathrm{C}$ with 120 minutes growth time. This current method suitable for large scale production of ZnO nanorods and could be extended to metal oxide nanostructures.
\end{abstract}

KEYWORDS: ZnO Nanorods, High Yield Chemical Synthesis, Microwave Radiation \& Hydrothermal Method

Received: May 05, 2017; Accepted: May 29, 2017; Published: Jun 21, 2017; Paper Id.: IJPRAUG20171

\section{INTRODUCTION}

$\mathrm{ZnO}$ nanostructures has attracted intensive research effort for its unique properties for versatile application [1]. ZnO nanorods are attracting much interest several applications such as nanophotonics [2], dyesensitized solar cells [3, 4], electron field emitters [5, 6], field effect transistors [7] and piezotronics [8]. Among various synthesis methods the microwave assisted hydrothermal synthesis has emerged as a powerful method for the synthesis of $\mathrm{ZnO}$ nanorods with some significant advantages such as cost effective large yield and less complicated technique [9]. Among several oxides semiconductors $\mathrm{ZnO}$ nanorods is considered to the best application material than other metal oxide nanorods [10]. Therefore the development of new, simple, cost effective and large scale synthesis roots for high quality $\mathrm{ZnO}$ nanorods is under investigation [11]. Now a days different nanostructures like nanowires, nanocombs, nanorings, nanobridges, nanoflowers, nanoblets, nanocages $[12,13]$ etc., are reported to their high potential application in nano electronic devices [14].

\section{EXPERIMENT}

In this method $\mathrm{ZnO}$ Nanorods are synthesized by a $0.5 \mathrm{Mol}$ solution of zinc acetate dehydrate $\left[\mathrm{Zn}\left(\mathrm{COOCH}_{3}\right)_{2}\left(\mathrm{H}_{2} \mathrm{O}_{2}\right)\right]$ was prepared by dissolving in $100 \mathrm{ml}$ of ethanol and stirred so much for $30 \mathrm{minutes}$ at $60^{\circ} \mathrm{C}$. Also $0.9 \mathrm{M}$ aqueous solution of sodium hydroxide $(\mathrm{NaOH})$ was prepared in a similar way with stirring for 30 minutes. The $60^{\circ} \mathrm{C}$ heated $0.9 \mathrm{M} \mathrm{NaOH}$ aqueous solution was added to drop by drop(slowly for 1 hour) touching the walls of the conical flask containing zinc acetate dehydrate $\left[\mathrm{Zn}\left(\mathrm{COOCH}_{3}\right)_{2}\left(\mathrm{H}_{2} \mathrm{O}_{2}\right)\right]$ solution under high constant speed stirring by magnetic stirrer. The solution turns into a jelly form and a milky white turbid 
solution was obtained after 2 hours. The solution was allowed to settle for 2 hours sealed. The turbid solution was then subjected to microwave radiation at a temperature of $150^{\circ} \mathrm{C}$ heated for 120 minutes. The product becomes fluffy inside the oven, removed and dried at room temperature and grinded, the obtained is a powder consists a mixture of $\mathrm{ZnO}$ Nanorods and Nanowires. The total procedure is repeated for different time durations in microwave chamber.

The growth time has also an important influence on the morphology of $\mathrm{ZnO}$ nanorods, nanowire in the hydrothermal process. A series of samples, of which the growth time varies from 30 minutes to 120 minutes, has been performed to better understand the growth kinetics.

\section{RESULTS AND DISCUSSIONS}

\subsection{X-ray Diffraction Analysis}

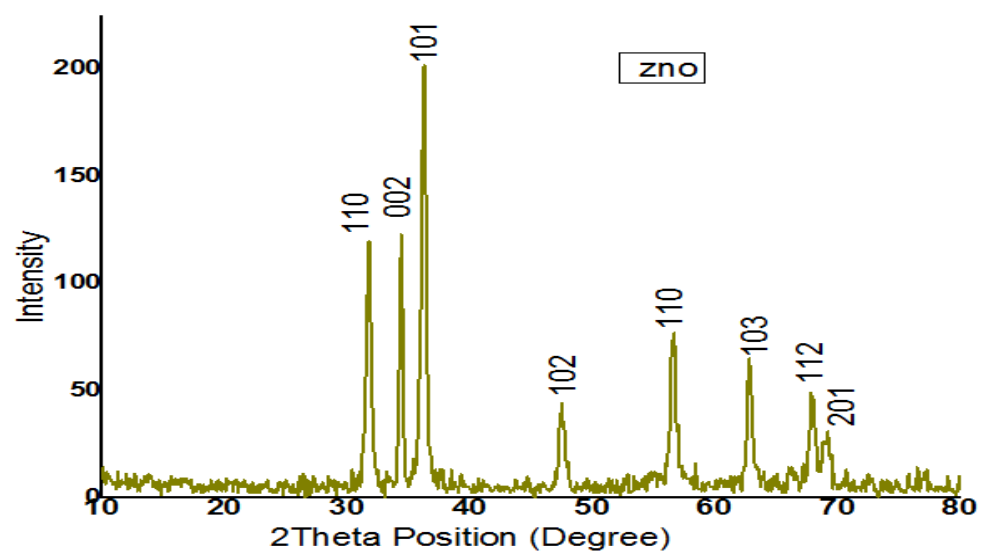

Figure 1: XRD Patterns of ZnO Nanorod

The phase and crystallinity of the synthesized sample were investigated by X-ray diffraction patterns shown in Figure 1. A number of Bragg reflections with $2 \theta$ values of $31.72^{\circ}, 34.30^{\circ}, 36.12^{\circ}, 47.51^{\circ}, 56.48^{\circ}, 62.75^{\circ}, 66.31^{\circ}, 67.83^{\circ}$, $69.04^{\circ}, 72.44^{\circ}$ and $76.81^{\circ}$ are observed corresponds to (100), (002), (101), (102), (110), (103), (200), (112), (201), (004) and (202) planes, shows a typical XRD pattern of $\mathrm{ZnO}$ nanoparticles in the range of $10^{\circ}-80^{\circ}$ at a scanning rate of 1 (JCPDS card No.89.1397). The average size of the zinc oxide nanoparticles was determined as $36 \mathrm{~nm}$ from the width of dominating peaks (100) and (101) reflections according to the Debye - Scherrer equation. All diffraction peaks are indexed according to the hexagonal phase of $\mathrm{ZnO}$ Nanorods. No characteristic peaks of impurity phases except $\mathrm{ZnO}$ are found which revealed that good crystalline in nature of the samples.

\subsection{Fourier Transform Infra-Red Spectroscopy Analysis}

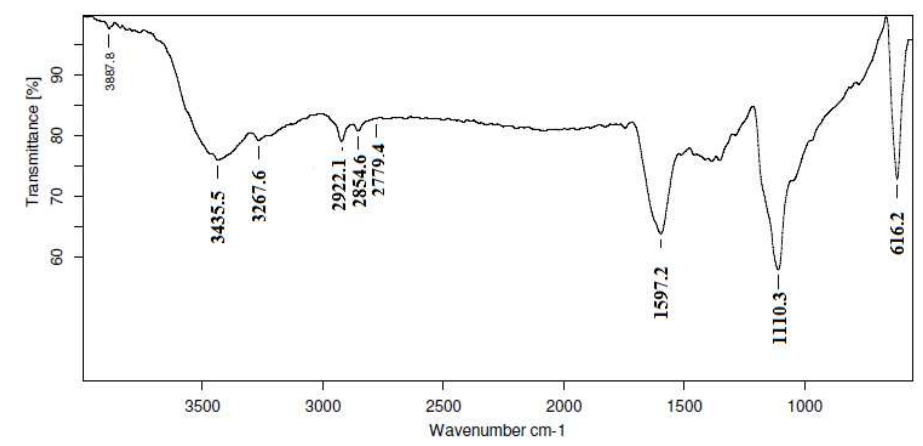

Figure 2: FTIR Spectra of ZnO Nanorod 
FTIR is an effective method to reveal the composition of products. Figure 2 is a typical FTIR spectrum of pure $\mathrm{ZnO}$ nanoparticles, the peak at $616.2 \mathrm{~cm}^{-1}$. The peaks lying from 1000 to 1600,2500 to 2900 and 3000 to4000 $\mathrm{cm}^{-1}$ are representing the functional groups corresponding to $\mathrm{C}-\mathrm{O}$ symmetric and anti- symmetric stretching mode, $\mathrm{C}-\mathrm{H}$ stretching mode and $\mathrm{O}-\mathrm{H}$ stretching mode respectively. The presence of the $\mathrm{O}-\mathrm{H}$ group represents the presence of water molecules on the surface of $\mathrm{ZnO}$ nanorods.

\subsection{Particle Size Analysis}

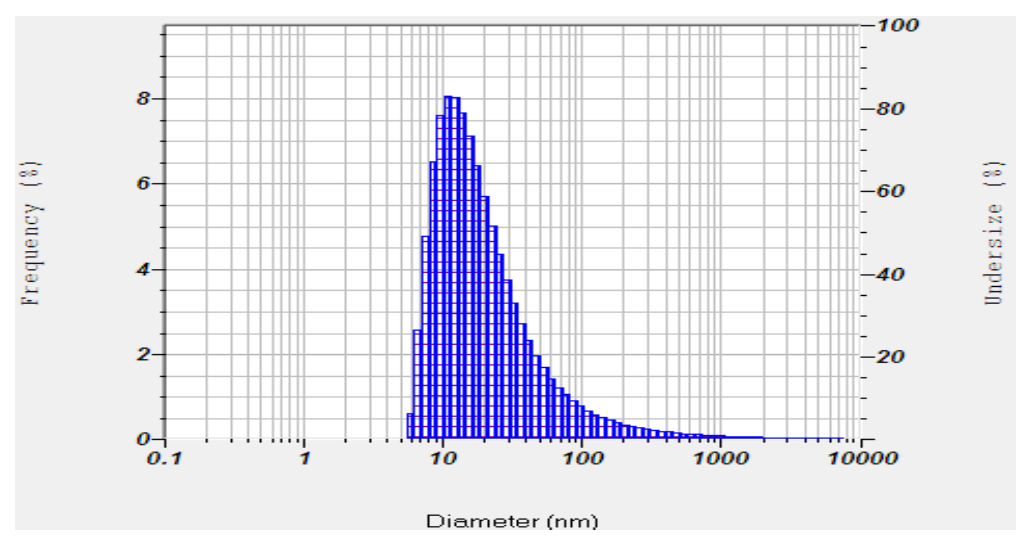

Figure 3: PSA Spectra of ZnO Nanorods

The as-prepared $\mathrm{ZnO}$ nanorods were ultra-sonicated and suspended in the distilled water. The measurement of particle size distribution of $\mathrm{ZnO}$ nanorods was done by Dynamic Light Scattering. In the prepared sample it was observed that, particle has wide size distribution; the majority of them were dispersed within a narrow range, as shown in Figure 3. The average particle size of the figure was found to be $42 \mathrm{~nm}$.

\subsection{Scanning Electron Microscope Analysis}

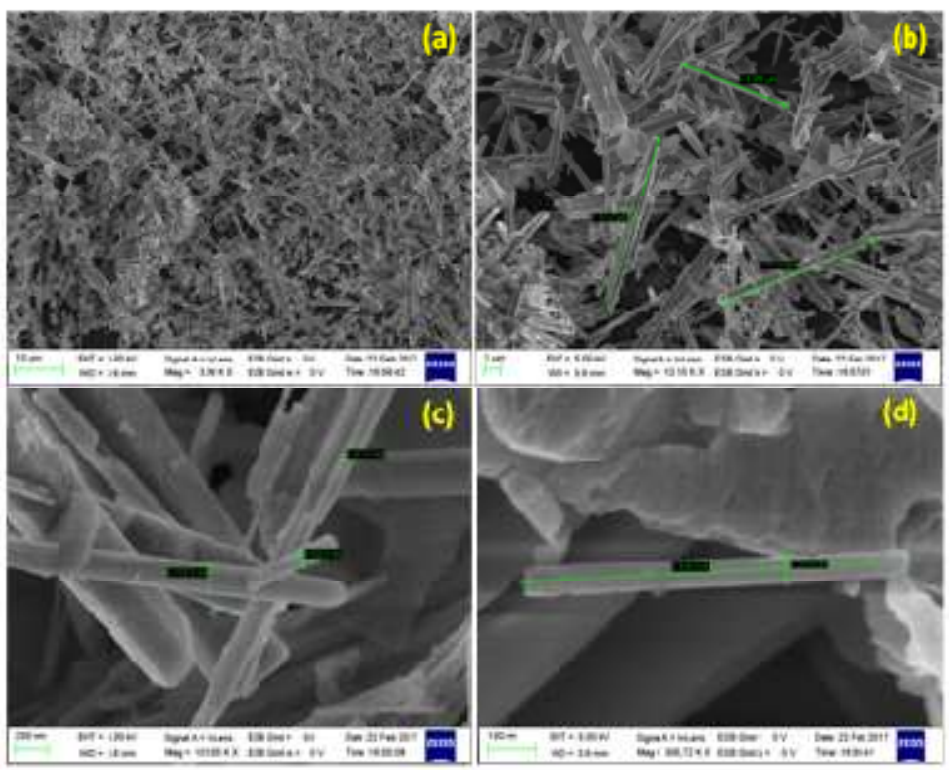

Figure 4: Figure (a) SEM Image Showing Uniform Growth of ZnO Nanorods. Figure (b and c) Shows Further Magnification (10KX) of ZnO Nanorods. Figure (d) Shows High Magnification (300KX) of Individual ZnO Nanorods with Uniform growth 
The FE-SEM micrographs of the as-prepared nanorods $\mathrm{ZnO}$ are presented in Figure 4. From figure (a) the sample uniform growth of $\mathrm{ZnO}$ nanorods on further magnification $(10 \mathrm{KX})$ in figures ( $\mathrm{b}$ and $\mathrm{c}$ ) the $\mathrm{ZnO}$ nanorods diameter around $55 \mathrm{~nm}$ and length is in few 0.8 micometer. Closer inspection with high magnification (300KX) in figure (d) shows individual $\mathrm{ZnO}$ Nano rods with uniform growth.

\subsection{UV-Vis Analysis}

The UV absorbance spectrum of $\mathrm{ZnO}$ nanorods is recorded in the wavelength range 300nm-800nm. Figure 5 shows the optical absorbance spectrum of $\mathrm{ZnO}$ nanorods synthesized by microwave irradiation at $150^{\circ} \mathrm{C}$. The spectrum shows a strongest absorption peak at 380nm. The powder containing mostly ZnO Nanorods shows much higher UV absorption as compared to nanoparticle which reveals the large surface area of nanorods as compared to nanoparticle. The slight shift in the absorption may occur upon the change in particle size or particle shape.

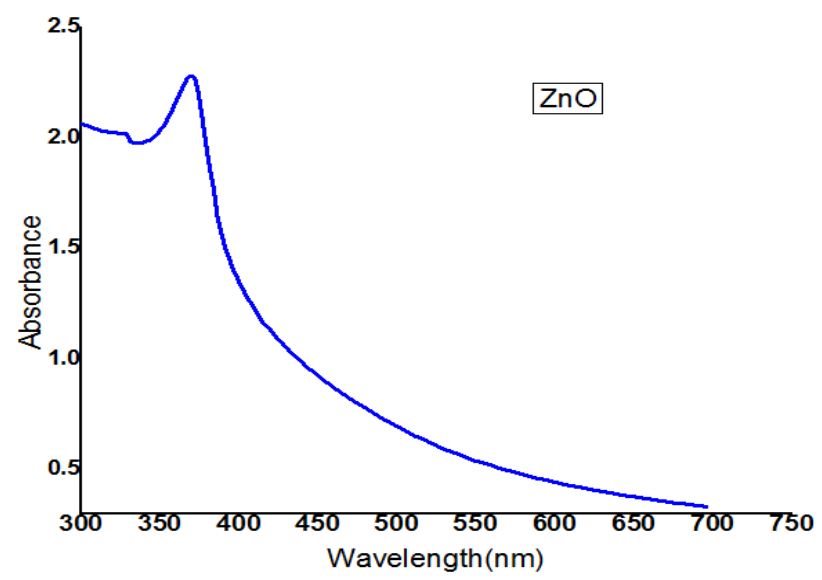

Figure 5: UV Absorbance Spectra of ZnO Nanorods

\section{CONCULSIONS}

The present work revealed a very simple approach for the synthesis of $\mathrm{ZnO}$ Nanorods by highly efficient microwave assisted hydrothermal method, which proved to be simple and reproducible for a variety of nanostructures in large scale. The XRD, PSA analysis confirms the size of ZnO Nanorods, SEM images revealed the spherical granular ZnO Nanorods, Zn-O stretching and deformation, vibration peaks were by disclosing by FTIR, and UV analysis technique confirmed the quantum size effect of $\mathrm{ZnO}$ Nanorods. The obtained $\mathrm{ZnO}$ nanorods are used in different research and industrial applications.

\section{ACKNOWLEDEGEMENTS}

The authors are thankful to the Department of the Physics, Director Research studies, Rayalaseema University and especially to the CNST, JNTUH for their constant cooperation throughout the work. One of the authors M. Chandra sekhar (PP. PHY.024), Research scholar, Rayalaseema university) would thank the management of Swarna Bharathi Institute of Science \& Technology (SBIT), Khammam for permitting to carry out research work. 


\section{REFERENCES}

1. M. H. Huang, S. Mao, H. Feick, H. Yan, Y. Wu, H. Kind, E. Weber, R. Russo, P. Yang, Science 292,1897 (2001). doi:10.1126/science.1060367.

2. R. Konenkap, R. C. Word, C. Schlegel, Appl. Phys. Lett. 85, 6004(2004). doi :10.1063/1.1836873.

3. M. Law, L. E. Greene, J. C. Johnson, R. Saykally, P. Yang. Nat. Mater. 4, 455 (2005). doi: 10.1038/nmat1387.

4. J. B. Baxter, E. S. Aydil, Appl. Phys. Lett. 86, 053114 (2005). doi:10.1063 / 1.1861510.

5. Y. K. Tseng, C. J. Huang, H, M. Cheng, I. N. Lin, K. S. Liu, I. C. Cheng, Adv. Funct. Mater. 13, 811 (2003). doi:10.1002/adfm.200304434.

6. A. Wei, X. W. Sun, C. X. Xu, Z. L. Dong, M. B. Yu, W. Huang, Appl. Phys. Lett. 88, 213102 (2006). doi:10.1063/1.2206249.

7. H. T. Ng, J. Han, T. Yamada, P. Nguyen, Y. P. Chen, M. Meyyappan, Nano Lett. 4, 1247 (2004). doi:1021/nl049461z

8. Z. L. Wang, Adv. Mater. 19, 889 (2007). doi:10.1002/adma.200602918.

9. J. Volk, T. Nagata, R. Erdelyi, I. Barsony, A. L. Toth et al., Nanoscale Res Lett.4, 699 (2009). doi:10.1007/s11671-009-9302-1.

10. Nicole Jones, Binata Ray Koodali T. Ranjit \&Adhar C. Manna, "Antibacterial activity of ZnO nanoparticle suspensions on a broad spectrum of microorganisms”, FEMS Microbiol Lett 279 (2008) 71-76.

11. Hongliang Zhu, Deren Yang, Hui Zhang "Simple Novel Low temperature Hydrothermal synthesis of ZnO Nanorods" Inorganic Materials, Vol.42. No.11, (2006), 1210-1214.

12. William L. Hughes and Zhong L. Wang, "Controlled synthesis and manipulation of ZnO nanorings and nanobows", Appl. Phys. Lett.86, 043106 (2005).

13. Xue-Lian Yu, Hui-Ming Ji, Hong-Li Wang, Jing Sun, Xi-Wen Du, “Synthesis and sensing properties of ZnO/ZnS Nanocages”, Nanoscale Res Lett (2010) 5:644-648.

14. Chittaranjan Bhakat, Prasoon Pal Singh, "Synthesis of ZnO Nanorods and its Applications in Solar cell”, IJMER, Vol.2, (2012) 2452-2454. 
